\title{
O NOVO PARADIGMA DA EDUCAÇÃO NA PROMOÇÃO DE UMA SOCIEDADE MAIS INCLUSIVA
}

\author{
EL NUEVO PARADIGMA DE LA EDUCACIÓN \\ EN LA PROMOCIÓN DE UNA SOCIEDAD MÁS INCLUSIVA
}

THE NEW PARADIGM OF EDUCATION
IN PROMOTING A MORE INCLUSIVE SOCIETY

Eduardo DUQUE ${ }^{1}$

JF DURÁN VÁZQUEZ ${ }^{2}$

RESUMO: O tema que aqui nos propomos tratar só é possível porque vivemos no tempo e no espaço em que vivemos. Vivemos nele, aqui e agora. Se estivéssemos no período pós II Guerra Mundial, poderíamos estar, possivelmente, a discutir a "escola de massas" ou, se estivéssemos no período de maio de 68 , estaríamos a debater a "contestação universitária". Hoje, porém, dado que a vida nos oferece outras oportunidades, discutimos o papel da educação à luz da Declaração Universal dos Direitos do Homem, conscientes do seu papel no desenvolvimento integral da pessoa. Esta nova forma de entender a educação faz com que o mundo dê um salto qualitativo, ao conceber-se em função do desenvolvimento pessoal de cada ser humano. Chegamos ao verdadeiro epicentro do sismo que abala a educação e que vai exigir profundas alterações ao subsistema escolar dentro do sistema educativo. A escola passa a ter, deste modo, a responsabilidade de adequar o currículo aos seus alunos e tomar opções que considere mais eficazes de forma a garantir o sucesso dos alunos - de todos os alunos -, de um modo especial, daqueles que manifestam algum tipo de fragilidade. No artigo que aqui nos propomos desenvolver, pretende-se repensar não exclusivamente o sistema escolar - que é determinante na formação da pessoa e que analisaremos pela via da diversidade escolar -, mas o sistema educativo como um todo e propor-lhe-emos que vá mais longe, mais ao concreto e mais ao fundo para ser verdadeiramente inclusivo, como se exige hoje nas sociedades contemporâneas.

PALAVRAS-CHAVE: Educação. Inclusão. Currículo. Cidadania. Direitos humanos.

RESUMEN: El tema que aquí nos proponemos tratar sólo es posible porque vivimos en el tiempo y en el espacio en que vivimos. Vivimos en él, aquí y ahora. Si estuviéramos en el período posterior a la Segunda Guerra Mundial, podríamos estar, posiblemente, a discutir la "escuela de masas" o, si estuviéramos en el período de mayo del 68, estaríamos debatiendo la "contestación universitaria". Hoy, sin embargo, dado que la vida nos ofrece otras oportunidades, discutimos el papel de la educación a la luz de la Declaración Universal de los Derechos Humanos, conscientes de su papel en el desarrollo integral de la persona. Esta

${ }^{1}$ Faculdade de Filosofia e Ciências Sociais da Universidade Católica Portuguesa (FFCS-UCP), Centro Regional de Braga, Braga - Portugal. Professor de Sociologia. OrcID: https://orcid.org/0000-0003-4719-3148. E-mail: eduardoduque@braga.ucp.pt

${ }^{2}$ Universidade de Vigo (UV), Facultad de Ciencias Jurídicas y del Trabajo. Professor de Sociologia. OrcID: http://orcid.org/0000-0002-7440-0168. E-mail: joseduran@uvigo.es

RIAEE - Revista Ibero-Americana de Estudos em Educação, Araraquara, v. 15, n. 1, p. 27-49, jan./mar. 2020. e-ISSN: $1982-5587$. 
nueva forma de entender la educación hace que el mundo dé un salto cualitativo, al concebirse en función del desarrollo personal de cada ser humano. Llegamos al verdadero epicentro del sismo que sacude la educación y que va a exigir profundas alteraciones al subsistema escolar dentro del sistema educativo. La escuela pasa a tener, de este modo, la responsabilidad de adecuar el currículo a sus alumnos y tomar opciones que considere más eficaces para garantizar el éxito de los alumnos - de todos los alumnos -, de un modo especial, de aquellos que manifiestan algún tipo de fragilidad. En el artículo que aquí nos proponemos desarrollar, se pretende repensar no exclusivamente el sistema escolar - que es determinante en la formación de la persona y que analizaremos por la vía de la diversidad escolar -, pero el sistema educativo como un todo y le propondremos que vaya más lejos, más al concreto y más al fondo para ser verdaderamente inclusivo, como se exige hoy en las sociedades contemporáneas.

PALABRAS CLAVE: Educación. Inclusión. Currículo. Ciudadanía. Derechos Humanos.

ABSTRACT: The theme that we propose here is only possible because we live in the time and space in which we live. We live in it, here and now. If we were in the post-World War II period, we might possibly be discussing the "mass schooling" or, if we were in the period of May 1968, we would be debating the "university contestation." Today, however, since life offers us other opportunities, we discuss the role of education in the light of the Universal Declaration of Human Rights, aware of its role in the integral development of the person. This new way of understanding education makes the world take a qualitative leap, when conceiving itself as a function of the personal development of each human being. We arrive at the real epicenter of the earthquake that shakes education and will require profound changes to the school subsystem within the education system. The school thus has the responsibility to adapt the curriculum to its students and to take options that it considers more effective in order to guarantee the success of the students - of all the students -, especially of those that manifest some type of fragility. In the article that we propose to develop, we intend to rethink not exclusively the school system - that is determinant in the formation of the person and that we will analyze by way of the school diversity -, but the educational system as a whole and we will propose that it goes farther, more to the concrete and further to the bottom to be truly inclusive, as is demanded today in contemporary societies.

KEYWORDS: Education. Inclusion. Curriculum. Citizenship. Human rights.

\section{Somos marcados pelo tempo em que vivemos}

O tempo e o espaço marcam os acontecimentos da história. É no tempo em que os factos históricos se realizam e dele dependem. Por isso, é que somos filhos do tempo, tudo se joga agora, em cada minuto. No tempo anterior ao nosso, não existíamos e no futuro a história é outra, pelo que é no presente que tudo acontece. Não é que não tenhamos memória, claro que sabemos que foi através dos outros que chegamos até aqui e que antes de nós já havia história. Podemos mesmo dizer com Odo Marquard (2003) que todos os homens são nascidos tardiamente (nascem depois do tempo). Quando começam não é no início. Antes de cada um 
já houve outros, em cujas tradições ou costumes somos nascidos, de modo que são a nossa origem, o nosso princípio a quem nos devemos ligar. Assim somos nós porque cada um chega tarde (nunca no princípio) e parte cedo (num tempo sempre novo).

Balzac (1951) dizia em A Solteirona que as épocas tingem os homens que passam por elas. Imprimem neles a sua marca característica e os moldam. Isto para dizer que somos cunhados pelo tempo, por ele construídos e por ele desfeitos. O tempo é tão complexo que faz e desfaz, não só dá a vida e a dissipa, como a marca de forma irrevogável. Portanto, ao analisarmos o tempo de uma determinada época, percebemos a densidade do pensamento, compreende-se as irradiações otimistas e derrotistas, as euforias e as neuroses, os temas brandos e os candentes. No campo da educação, encontramos tempos de trevas e iluminados, ignorâncias e tempos esclarecidos, mais canónicos e mais tendentes para a rebeldia, mais obedientes e independentes.

O tempo e o espaço condensam definitivamente a conceção da sociedade. Se viajarmos pela história, quantas épocas se encontram provenientes de diferentes conceções sociais, de modelos educacionais diferentes, de diversas estruturas de desenvolvimento, de formas distintas de organização da vida! Por exemplo, no século XII, o espírito da época é sustentado pela organização do feudalismo e, no século XIII, reflete-se um clima de uma vida melhor do que em épocas anteriores; renasce o sentido da propriedade, antes depreciado pelo despotismo feudal. Já no século XIV, afirma-se uma procura de uma vida mais luxuosa, muito consentânea com o início do espírito burguês. Os séculos XV e XVI, revelam-se mais incapazes para aspirações transcendentes, são mais voltados à ciência, à afirmação do mundano e da busca da fama. O século XVII é marcado pela revolução científica, levada a cabo sobretudo por Galileu Galilei, e por profundos conflitos religiosos e políticos. Já o século seguinte, torna-se histórico pela exaltação da razão, é o século das luzes. O século XIX é marcado pela Revolução Industrial e pela consequente nova ordem económica. No século $\mathrm{XX}$, dão-se as duas grandes Guerras Mundiais, que afetam drasticamente o comportamento político e social, e registam-se grandes invenções tecnológicas (DUQUE, 2014, p. 157-158). Enfim, poder-se-ia continuar a descrever a direção das sociedades ou as tendências de desenvolvimento até aos nossos dias, mas, tal não se justifica, dado que o que se pretende acentuar é que cada época visa a materialização de um determinado tempo, um determinado enquistamento criativo, localizações precisas, delimitação entre fronteiras cronológicas.

E como é que poderíamos descrever o tempo do nosso tempo? 
Aristóteles (IV, 14, 223 a), na sua Física, diria que este tempo precisa de alma. Viveremos realmente uma época, originalmente rebelde, que abriu ruturas nos modelos sociais vigentes e que exige um rasgo de horizonte, novos modelos de educação?

Segundo Innerarity (2011, p. 19) "uma das consequências da tão frequente proclamada crise da ideia do progresso consiste em o futuro se tornar problemático e o presente se absolutizar". Ora, as políticas estão voltadas para o presente, têm um olhar curto, atendem ao urgente e não prioritário. E sabemos bem que o prioritário tem um horizonte bem mais dilatado do que a miopia do urgente, em que tudo tem de ser resolvido no imediato, numa aceleração tamanha que tende a anular qualquer pensamento ou reflexão.

Vive-se de forma tão célere e agitada que o futuro pode esfumar-se nas tarefas do diaa-dia. As novas tecnologias não são alheias a este fenómeno. Bem pelo contrário, contribuíram para o seu sucesso. A inovação ganhou velocidade; o balanço é muito e convoca, por vezes, uma certa náusea. Teria razão Sartre ao dizer que "a vida é uma paixão inútil”! O que hoje se inventou amanhã está em desuso e passa a ser passado. Passado pobre porque nem história fez. E o que a história faz é narrar a vida no tempo.

O tempo presente está repleto de sinais de descontinuidade, são sinais paradoxais; por lado, exprime-se a satisfação com a vida, a plenitude de felicidade, por outro, encontra-se a crise e a inexorável deterioração que ela acarreta, que levanta novas dúvidas sobre a matéria de que é construído o presente (DUQUE, 2014).

O presente é demasiado complexo, cruza processos, linguagens e estilos que eram até então inconciliáveis e tudo acontece numa vigorosa imprevisibilidade de movimentos, não permitindo antever qualquer futuro. "O futuro privatiza-se, pluraliza-se e fragmenta-se. Temos uma ideia privada da felicidade, que já não está associada a projetos coletivos nem é entendida como algo possibilitado por um contexto social" (INNERARITY, 2011, p. 151). Será o tempo presente de que aqui falamos verdadeiramente inclusivo? Terá espaço para integrar pessoas diferentes? Não será ele constituído por dinâmicas demasiado incertas e fluídas que vão contra o princípio da inclusão, que, a priori, implica um tempo mais pausado, um novo olhar sobre as coisas e uma paragem nos pormenores?

Antes de avançarmos por aqui, vejamos o interesse que a educação despertou ao longo da história. 


\section{O interesse pela Educação}

Já vem de longe o interesse pela educação. Mesmo muito antes das sociedades industriais este interesse esta patente. No remoto século $\mathrm{XV}$, a educação não tinha um significado ligado aos processos materiais da vida humana. Para os grupos sociais mais pecuniosos, a educação visava uma preparação para o desempenho das ocupações políticas e religiosas, bem como a socialização numa série de normas de conduta e valores ligados à civilidade. $\mathrm{O}$ aspeto mais formal desta educação será desenvolvido, especialmente a partir do século XVI, concretamente nas escolas religiosas nascidas da Contrarreforma (DURKHEIM, 1992, p. 293). Os membros dos grupos sociais menos favorecidos eram educados, em regra geral, no seu próprio ambiente social. Apenas alguns frequentavam as escolas paroquiais para receber uma formação muito básica, essencialmente, algum doutrinamento religioso (VARELA-ÁLVAREZ URÍA, 1991, p. 68).

Esta situação irá progressivamente sendo alterada com o aparecimento da sociedade industrial (EWEN, 1983, p. 119).

A escola será percebida neste contexto como um campo destinado a fomentar o conhecimento e as formas de socialização que a sociedade nascente precisava (POLLARD, 1987, p. 242-258). Essa tendência começará a ser notada no século XVIII na Inglaterra, onde determinados religiosos, como Rev. Turner, observavam as escolas como "um espetáculo de ordem e regularidade" (apud FERNÁNDEZ ENGUITA, 1990, p. 127). Mas será especialmente durante o século XIX, e durante as primeiras décadas do séc. XX, quando as diferentes elites sociais tomarão consciência da necessidade de se criar escolas.

A escola emergiu assim, no contexto da sociedade industrial, como uma instituição necessariamente eficiente, hierárquica e disciplinar, de acordo com as regras e normas morais exigidas pelo mundo do trabalho assalariado. Com este caráter se irá institucionalizando a partir da segunda metade do século XIX, tanto na Europa como na América.

Apesar disto, é de realçar que a expansão dos sistemas educacionais na maioria dos países ocidentais não ocorrerá até à Segunda Guerra Mundial. Na verdade, num contexto de forte crescimento económico, a educação foi promovida como um dos principais agentes desse crescimento (ORTEGA, 1993, p. 89). E, portanto, também como um dos instrumentos mais importantes da ideologia moderna da realização pessoal. A hierarquia nela prevalecente, com todas as suas regularidades disciplinares (FOUCAULT, 1999), foi percebida como a contrapartida necessária ao esforço exigido pelo sucesso académico. 
Os que não concordaram com este regime disciplinar, porque não aspiravam a conquistas académicas futuras, aceitaram as outras disciplinas do mundo do trabalho, porque também tinham as suas recompensas. De fato, como Paul Willis apontou no seu clássico estudo de contracultura escolar na Inglaterra, em meados da década de 1970 (WILLIS, 1988), essa atitude estava diretamente relacionada com a cultura da fábrica. Tal facto, implicava uma rejeição de tudo o que se relacionava com o mundo académico, na mesma medida em que implicava a aceitação de muitos dos valores da cultura do trabalho.

Desta forma, mesmo que indiretamente, a cultura escolar, em vez de se opor à cultura do trabalho, reforçou-a. Na verdade, os jovens que não tinham qualquer interesse na escola, nas suas propostas académicas e nos seus requisitos disciplinares, no entanto, aceitavam com prazer essas outras disciplinas.

Desta forma, a cultura escolar e a cultura do trabalho mantinham a sua coerência, produzindo e reproduzindo as suas diferentes ordens hierárquicas e disciplinares. Na verdade, aqueles que aceitavam a primeira destas culturas também assumiam as suas disciplinas; aqueles que, pelo contrário, a rejeitavam, admitiam, no entanto, a hierarquia e a autoridade da cultura da fábrica.

Esta situação era típica de um momento em que a cultura do trabalho se mantinha viva em grande parte da juventude e em que ainda era possível desenvolver essa cultura sem os obstáculos do desemprego juvenil.

Toda essa realidade começará a mudar, especialmente desde a década de 1980, à medida que as taxas de desemprego juvenil aumentaram, mesmo nos setores que possuíam credenciais académicas (BECK, 2006, p. 144).

Nesse cenário, em que a educação flexibilizava cada vez mais as suas relações com o mundo do emprego e em que os jovens que abandonavam precocemente o sistema educativo estavam com dificuldades em encontrar trabalho, as estruturas disciplinares relacionadas com o mundo do trabalho e da educação começaram a perder força e, naturalmente, a não ser inclusivas.

\section{O processo da inclusão}

A inclusão visa, segundo Ainscow (2008), essencialmente, a transformação do sistema educacional, de forma a encontrar meios de alcançar níveis que não estavam a ser contemplados no sistema educativo. Afonso (2005) refere que compatibilizar a igualdade de direitos (sociais, cívicos etc.) com o respeito pela individualidade assegura-se um dos grandes 
dilemas da atualidade. De facto, reconhece-se na sociedade hodierna uma tendência para a homogeneização de identidades, valores e culturas. Neste sentido, não podemos conceber o conceito de inclusão como uma "tentativa" de igualar as diferentes identidades. Segundo Santos (2001), uma vez que todas as culturas tendem a distribuir pessoas e grupos de acordo com dois princípios concorrentes de pertença hierárquica, e, portanto, com conceções concorrentes de igualdade e diferença, as pessoas e os grupos sociais têm o direito a ser iguais quando a diferença os inferioriza, e o direito a ser diferentes quando a igualdade os descaracteriza. Segundo Ainscow (1999), o sistema e as práticas educativas devem assegurar a gestão da diversidade assim como a mobilização de diferentes tipos de estratégias que permitam responder às necessidades educativas dos alunos, promovendo competências universais que permitam a autonomia e acesso à cidadania plena por parte de todos.

Falar de uma sociedade inclusiva implica, necessariamente, falar do papel que a escola, reflexo da diversidade, assume neste contexto. Desta forma, não se assume aqui a escola inclusiva como uma resposta adequada para alunos diferentes, mas como uma resposta potencialmente melhor para todos, quaisquer que sejam as suas características. No entanto, isso não significa o esvaziamento das diferenças, mas o reconhecimento do seu valor acrescentado, ou se quisermos, de que a diversidade é uma mais valia (AFONSO, 2005). Todavia, e segundo Rodrigues (2003), há um aluno-tipo ideal que assenta no mito da homogeneidade como um fator de qualidade das escolas. Este "aluno-tipo" ainda está bem patente na sociedade, transmitindo que para todos terem as mesmas oportunidades educativas, devem fazer exatamente o mesmo, ao mesmo tempo (AFONSO, 2005). Neste sentido, determinados alunos poderão ser vistos como agentes perturbadores do "normal" funcionamento da escola e mesmo como sendo a causa do insucesso da turma. Ainscow (2008) compreende a inclusão como um processo tripartido: presença na escola e uma participação ativa; proporcionar as condições necessárias para que o aluno realmente participe das múltiplas atividades escolares e, por último, a aquisição de conhecimentos. Neste sentido, a inclusão implica a presença do aluno na escola de forma a que possa aprender e desenvolver as suas potencialidades.

\section{Organização curricular do sistema educativo}

Importa aqui termos como ponto de partida o que se entende por currículo e as suas diversas amplitudes. Partimos, assim, do sentido mais elementar da palavra currículo, em que surge como termo com origem latina da palavra currere e que tem como sentido primário o 
significado de caminho, percurso ou trajeto. Daqui depreende-se que ao abordar a temática do currículo estaremos a analisar um conceito que implica a noção base de percurso a percorrer, ou seja, um caminho que deverá estar previamente traçado e proposto.

No campo da Educação, currículo pode ser considerado em sentido restrito como um plano estruturado de ensino, onde são propostos determinados objetivos e conteúdos, bem como algumas orientações didáticas e metodológicas.

Num sentido mais amplo, podemos considerar que o currículo é o conjunto de ações desenvolvidas pela escola no sentido da promoção da aprendizagem dos seus alunos, na medida que abrange não só as experiências programadas e realizadas na escola, como também o conjunto de experiências vivenciadas pelos alunos, fazendo com que o acesso ao currículo seja, de facto, significativo para o crescimento dos aprendentes, inserindo na sua própria definição a ideia de currículo formal e de currículo real (ZABALZA, p. 1999).

O termo currículo tem-se vulgarizado na linguagem educativa, já que é um conceito que se tem aplicada a diversos domínios. Ribeiro (PACHECO, 2001), refere que:

[...] sendo o currículo um conceito polissémico, carregado de ambiguidades [...] não possui um sentido unívoco, existindo na diversidade de funções e de conceitos em função das perspetivas que se adotam, o que vem a traduzir-se, por vezes, em alguma imprecisão acerca da natureza e âmbito do currículo". (p. 15)

Partindo da diversidade de conceitos e teorias que caraterizam o currículo e que são apresentados por vários autores (SILVA, 2000; SILVA; MOREIRA, 2001; PINAR, 2007), entendemos currículo como um termo que encerra sentidos diversos, sobretudo porque também é diferente o modo como se olha para a educação e para o que é a sua razão de ser: o conhecimento. Por isso, e enquanto construção social, política e ideológica, o currículo é discutido pelo conhecimento, como o fundamentam as teorias curriculares que têm sido propostas a partir, por exemplo, do quadro conceptual Habermas (1990).

Na perspetiva de Bautista (1993), currículo pode ser entendido como um conjunto de conhecimentos, capacidades, valores e normas de comportamento que devem ser transmitidas pela escola às crianças e jovens. Ainda que abra um pouco mais este sentido quando refere que o conceito de currículo deve também ser entendido como o conjunto de experiências que a escola, como instituição, põe ao serviço dos alunos com o fim de potenciar o seu desenvolvimento integral.

Já para Torres González (2002), o currículo é entendido como um instrumento que a escola possui que lhe permite adaptar-se às necessidades dos alunos. A sua construção 
depende dos órgãos administrativos das escolas e das políticas nacionais, mas as decisões relativamente à forma como se adapta ao contexto escolar e aos alunos que o frequentam, envolve os professores e o trabalho de colaboração entre eles.

Atendendo às características da escola inclusiva, são vários os autores que se debruçam sobre esta questão. Brennan (1990) analisa os aspetos que o currículo comum terá que incluir para responder à heterogeneidade de uma escola e às necessidades individuais dos alunos:

- Relevante nos conteúdos, tendo em conta a experiência e as características das crianças;

- Flexível, partindo das necessidades dos alunos e da metodologia dos professores e deve permitir mudanças face aos diferentes contextos escolares, dando assim alguma autonomia aos professores.

- Amplo, o que, segundo o autor, implica a colaboração entre os intervenientes na organização escolar (pais, professores, órgãos de liderança, comunidade).

Na conceção de Roldão (2003), o currículo deve ser entendido como um constructo social, em permanente situação de desconstrução, negociação e reconstrução, protagonizadas pelo conjunto de instâncias e atores envolvidos, com os seus diversos campos e níveis de poder.

Por outro lado, e como complemento à informação analisada, Correia (2008) salienta que é indispensável que os currículos não coloquem de lado os interesses, as expectativas, as opiniões das novas gerações, bem como as necessidades dos que precisem de uma atenção especial dentro dessas novas gerações.

Vemos, desta forma, e recorrendo a uma breve revisão da literatura sobre o conceito em causa, que existem diversas teorias curriculares que se relacionam com diferentes conceções de currículo, mas que se cruzam em visões comuns das finalidades do currículo. $\mathrm{O}$ que daqui se pode depreender é que as diferentes conceções apresentadas de currículo correspondem a diferentes formas de equacionar os dilemas colocados por Contreras (1990, apud PACHECO, 2001), quando apresenta a seguinte problemática:

[...] o currículo deve propor o que se deve ensinar ou aquilo que os alunos devem aprender? O currículo é o que se deve ensinar e aprender ou é também o que se ensina e aprende na prática? O currículo é o que se deve ensinar e aprender ou inclui também a metodologia e os processos de ensino? O currículo é algo especificado, delimitado ou acabado que logo se 
aplica ou é de igual modo aberto que se delimita no próprio processo de aplicação? (p. 17).

Esta perspetiva realça aquilo que é verdadeiramente o conceito que cada autor tem do que é um currículo, na medida em que, abrange uma quantidade de dimensões relacionadas entre si, semelhante a uma teia, mas que exige, da parte do educador/professor, a capacidade de assumir a responsabilidade de decidir e gerir o currículo da forma que considerar mais adequada, convidando o aluno a participar na sua construção, definindo, juntamente com os demais professores, linhas orientadoras para a definição de caminhos que clarifiquem o papel que a escola deve assumir em determinados contextos. Nesta perspetiva, o professor é o construtor do currículo, baseando-se nos seus conhecimentos, na sua experiência, mas contando com a colaboração dos restantes agentes educativos que se coresponsabilizam em todo este processo (SILVA, 2011).

Não obstante esta consciência do papel do professor no desenho curricular, o processo de construção do currículo deve ser compreendido como um processo contínuo de decisões que podem ocorrer em diferentes contextos, passando por diversas etapas a um nível mais ou menos amplo. A esse respeito Pacheco (2001) apresenta três níveis de decisão curricular: a do contexto político-administrativo (administração central), a do contexto de gestão (administração regional e local) e a do contexto de realização (sala de aula).

O contexto político-administrativo associa-se ao currículo formal, oficial, comum a todo o sistema de ensino que resulta de uma decisão política e administrativa, apresentando-se como uma função normativa do próprio ensino e onde são especificadas as experiências educativas a que os alunos deverão ter acesso numa determinada área e/ou ano de escolaridade. O contexto de gestão refere-se à exploração do currículo ao nível da região e da escola, onde serão efetuadas as adaptações das prescrições e a interpretação das orientações apresentadas pelos órgãos superiores. Esta é uma fase de grande importância para o sucesso da implementação do currículo, pois importa que a escola participe ativamente na adaptação e construção curricular, evitando apenas implementar o currículo de forma taxativa e pouco reflexiva. O projeto educativo da escola, o projeto curricular de escola e os Planos de Turma situam-se neste contexto de decisão curricular, que se desenvolve ao nível da escola. Por fim, o último nível de decisão curricular é o contexto de realização que consiste, basicamente, no planeamento e realização curricular. É a este nível que se desenvolve a interação pedagógica entre professor/aluno e aluno/aluno. É neste âmbito que o professor fará a organização e a gestão do espaço, do tempo, das atividades de modo a proporcionar as experiências de 
aprendizagem que permitam aos alunos atingir as competências instrucionais ou sociais patentes nos projetos realizados ao nível da gestão (PACHECO, 2001).

As recentes orientações de políticas educativas em Portugal (que é o caso que melhor conheço, mas, possivelmente, acontecerá o mesmo em Moçambique), consagradas em documentos legislativos em vigor, bem como a crescente heterogeneidade nas escolas, têm vindo a introduzir novos desafios de organização e gestão escolar, bem como às estratégias pedagógicas aplicadas pelos diferentes profissionais de educação. O que está em causa é que as escolas consigam gerir de forma mais flexível o currículo, adequando-o às características e diversidades próprias de crianças e jovens que as frequentam.

As reflexões incidem basicamente na clássica problemática curricular apresentada por Roldão (2003): "ensinar o quê a quem, para quê e como", mas, para tal, importa que as escolas reequacionem as suas respostas a estas questões à luz da diversidade atual da população escolar.

\section{Uma escola flexível e aberta à diversidade}

Até ao momento estivemos a refletir, ainda que de um modo muito sucinto, sobre o sentido do currículo e a forma como este deve ser estruturado nos diferentes estados de execução: ministério, escola e sala de aula. Partimos, assim, do pressuposto de que as opções curriculares são definidas de acordo com as escolas, as turmas, os indivíduos, permitindo facilitar o acesso às competências previstas no currículo comum, como um marco de referência. A partir do currículo vão-se estreitando as adequações de um nível macro a um nível micro, ou seja, passando pelos Projetos Curriculares de Escola, pelos Planos de Turma e, se necessário, pelas Adequações Curriculares Individualizadas, pois, importa que a diferenciação curricular, que deve ser adotada nos diferentes estados de execução, não assuma contornos discriminatórios, pressupondo a aceitação da diversidade como norma. Esta decorre da heterogeneidade natural dos indivíduos, resultante das suas características pessoais, sociais, culturais, mas também da natural diversidade das condições específicas de cada aluno.

$\mathrm{Na}$ verdade, muitos foram os fatores sociais e educativos que colocaram em destaque na agenda da Europa a discussão sobre a problemática da exclusão, de um modo especial a exclusão escolar. Os níveis de insucesso e o abandono escolar ou até mesmo o não acesso à escolarização têm vindo a ser centro das atenções, pelo menos no que toca a análises mais académicas ou apresentadas por organizações internacionais de cariz educativo. 
A este propósito a Lei de Bases do Sistema Educativo Português, aprovada em 1986 e alterada em 1997 e em 2005, define enquanto princípios gerais a responsabilização do Estado na promoção da democratização do ensino, garantindo o direito a uma justa e efetiva igualdade de oportunidades no acesso e sucesso escolares. Desta forma, o sistema educativo organiza-se de forma a assegurar o direito à diferença, o respeito pelas personalidades e pelos projetos individuais de cada um, bem como da consideração e valorização dos diferentes saberes e culturas.

Sobre esta questão Roldão (1999) refere que:

[...]é o reconhecimento efetivo do direito de todos a uma educação de qualidade que coloca no centro dos problemas curriculares do nosso tempo a necessidade de reinventar a escola, de modo a que se possa oferecer e construir o currículo como um percurso diferenciado e significativo que, através de opções diferentes, possa tornar mais semelhante o nível de competências à saída do sistema escolar, competências de que todos precisarão igualmente, e de que dependerá, sem dúvida, o sucesso social e pessoal das suas vidas (p. 28).

Não há dúvida de que a relação da escola e dos professores com o currículo tem sofrido alterações significativas nos últimos tempos, que decorrem, em grande parte, da expansão da escolaridade obrigatória, com o alargamento da escolaridade obrigatória de 9 para 12 anos escolares e de 14 para 18 anos de idade (Lei 85/2009 de 27/8), e que obrigou ao questionamento das finalidades e dos conteúdos curriculares, e também das representações sociais e pedagógicas do aluno.

Contudo, ainda que esteja salvaguardado o acesso alargado ao ensino, não se encontra, porém, garantido o sucesso. A escola abriu-se a uma nova população, a novos utentes sendo na sua essência interclassista, ou seja, no mesmo espaço podemos ter crianças oriundas dos mais variados níveis socioeconómicos e culturais e até de diferentes nacionalidades dada a crescente e recente procura de Portugal como país de acolhimento de imigrantes.

Assim, a grande diversidade de alunos com identidades culturais, linguísticas, socioeconómicas e com processos e ritmos de aprendizagem próprios reclama abordagens curriculares diferentes, conceptualizadas e operacionalizadas na ação pedagógica da escola. Sendo que uma escola que se pretende cada vez mais inclusiva, tem de ser reiterada através do desenvolvimento de projetos curriculares que tenham como premissa conceber, gerir, implementar e avaliar os resultados de percursos curriculares diversificados que reconheçam e satisfaçam as necessidades educativas dos seus alunos.

É à luz da filosofia inclusiva que os professores tentam dar resposta às necessidades educativas de todos os alunos, o que constitui um dos maiores desafios da escola dos nossos 
dias. Um desses desafios está ligado às novas perspetivas sobre o currículo nas quais a flexibilidade curricular e a implementação de novos modelos pedagógicos de cooperação e de diferenciação garantam o direito de acesso e a igualdade de condições para o sucesso de todos os alunos numa escola para todos, (NIZA, 1996).

Ao contrário do que muitos educadores possam pensar, a flexibilidade do currículo, de acordo com a diversidade que cartografa o espaço escolar atual, não tem que implicar uma limitação das aprendizagens a realizar, uma vez que pode ser desenvolvida através de alterações qualitativas e não forçosamente quantitativas (ROLDÃO, 1999); pelo contrário, parece-nos que deve ter como finalidade última garantir que as competências de saída de cada ciclo de escolaridade, bem como a transição para a vida pós-escolar, sejam alcançadas por todos os alunos, ainda que através de diferentes percursos e tendo como principal ponto de partida a diversidade.

É, realmente, na escola que se podem operar grandes mudanças ao nível da inclusão, tal como é referido na Declaração de Salamanca (1994), quando refere que "as escolas regulares constituem os meios mais capazes de combater as atitudes discriminatórias, criando comunidades abertas e solidárias, construindo uma sociedade inclusiva e atingindo uma educação para todos".

Falar em inclusão já não é um conceito abstrato ou pouco claro para os profissionais educativos, esta não só é uma diretiva do nosso sistema de ensino, como é aceite atualmente pelas escolas e pelos professores como um bem necessário. No entanto, nas salas de aula, na realidade escolar dos professores e alunos, a aplicação desta diretiva torna-se bem mais complicada, já que nem sempre os professores sentem a segurança necessária e consideram ter os conhecimentos necessários para agir adequadamente perante estas situações. Esta perspetiva está bem presente num estudo realizado por Leite (2005) relativo às dificuldades sentidas pelos professores na concretização da inclusão, no qual se refere que, em muitas situações, a inclusão se constitui como um fator de insatisfação pessoal e profissional para o professor, existindo "necessidades de formação ao nível da mudança de atitudes face à diferença". Os professores têm consciência que lhes cabe a importante tarefa de individualizar o ensino para poderem garantir o sucesso de todos os alunos, no entanto, fatores diversos, tais como: a falta de formação, como já mencionamos anteriormente; as dificuldades na gestão do tempo; a falta de trabalho colaborativo; as condições de trabalho proporcionadas (número elevado de alunos e vários anos de escolaridade numa mesma turma) dificultam a sua tarefa, revelando dificuldades na sua intervenção em turmas inclusivas. 
Decorrente desta tendência crescente da política educativa para a integração, surgiu, há alguns anos a esta parte, com o Relatório Warnock, no Reino Unido (1978), o conceito de Necessidades Educativas Especiais (NEE). Porém, uma vez que esta temática é muito extensa não a vamos tratar aqui, pelo que a nossa análise se circunscreve ao estudo da inclusão no seu sentido lato e não particular.

Não obstante, é importante realçar o impacto que o processo de inclusão dos alunos com NEE teve nas escolas, já que forçou a adoção de novos modelos de intervenção, de um modo especial, substituindo o modelo clínico ou médico-pedagógico, centrado na deficiência de intervenção em ensino especial, pelo modelo sócio antropológico, social, ou ecológico, envolvendo e responsabilizando um maior número de intervenientes. Passa a existir, assim, uma equipa multidisciplinar proporcionadora de um relacionamento e intercâmbio direto e sistemático de todos os intervenientes da ação educativa (pais, professores de educação especial, do ensino regular, psicólogos, técnicos, direção, autarquia), havendo consequentemente uma atitude colaborativa tendo por objetivo a melhoria das condições de sucesso para todos os alunos e, de um modo especial, para os alunos com necessidades educativas (AINSCOW, 1999).

\section{A implementação de novos modelos pedagógicos}

Como referimos anteriormente, na contemporaneidade, só se consegue pensar a escola numa perspetiva inclusiva, pelo que isso exige que a escola esteja muito atenta a acolher novos projetos, assuma uma atitude de constante abertura e esteja disponível para implementar novos modelos pedagógicos.

Neste sentido, torna-se fundamental a identificação e a avaliação das necessidades educativas numa tónica qualitativa, centrada na caracterização funcional dos alunos e não nos seus défices; percebendo aquilo que os alunos são capazes e quais as respostas de que necessita.

A diferenciação pedagógica/curricular é, assim, entendida como um princípio fundamental da escola inclusiva. Assim, flexibilidade do currículo e diferenciação curricular são conceitos interligados, uma vez que não é possível diferenciar se não existir flexibilidade curricular. Madureira e Leite (2003) dizem que "um currículo aberto permite organizar de forma flexível a estrutura e sequencialização das aprendizagens, bem como os processos de ensino a desenvolver para atingir essas aprendizagens" (p.92). Os mesmos autores referem ainda que só através de um currículo aberto e flexível, que permita aos professores fazer as 
adequações necessárias que vão ao encontro das aprendizagens consideradas socialmente significativas e relevantes para uma dada população e para cada um individualmente, é que o a noção de currículo poderá fazer sentido e ter um conceito de utilidade para os alunos. Isto porque a gestão do currículo de forma flexível permite que sejam feitas diversas adaptações do programa oficial para os alunos com necessidades educativas especiais, tendo em conta tudo aquilo que o aluno consegue realizar em sala de aula, com os seus pares, considerando que a diferenciação pode facilitar o acesso ao currículo comum e, portanto, a aquisição de competências finais de ciclo de escolaridade e a transição para a vida pós-escolar.

Na perspetiva de Rodrigues (2006), e num sentido mais lato, o conceito de adequação de novos modelos pedagógicos tem como ponto de partida o currículo nacional definido, com os ajustamentos ou modificações que é necessário introduzir no currículo nacional, com vista à sua contextualização até ao nível da turma e do aluno.

Torres Gonzalez (2002) hierarquiza diferentes tipos de adequações: por um lado, apresenta as adequações de acesso ao currículo que dizem respeito ao uso de recursos especiais, materiais ou de comunicação, que facilitarão o acesso ao currículo comum; por outro, as adequações curriculares que se traduzem nas "modificações que são realizadas na programação dos objetivos, conteúdos, metodologias, atividades, critérios e procedimentos de avaliação para fazer face às diferenças individuais" (p. 164). Estas podem dividir-se em dois tipos: adequações curriculares não significativas operacionalizadas nas modificações ocorridas nos diferentes elementos da programação, planeadas para o ciclo de ensino e ou turma, mas que não afetam as aprendizagens básicas e fundamentais do currículo oficial; e as adequações curriculares significativas traduzidas em grandes modificações e/ou cortes na programação inicial havendo eliminação de algumas aprendizagens básicas, do currículo oficial, em termos de objetivos, conteúdos e critérios de avaliação.

As adequações não significativas são menos específicas e correspondem apenas a ligeiras alterações na orientação e metodologia do professor quando põe em ação a planificação habitual, enquanto as adequações curriculares significativas, pelo contrário, são alvo de maiores modificações que podem consistir na redução de conteúdos, bem como na elaboração de instrumentos de avaliação e modificação de critérios.

Vemos assim que a aplicação de medidas de adequação curricular é, na perspetiva de Leite (2005), uma resposta às necessidades educativas especiais enquanto processo dinâmico e funcional que tem em conta as características do aluno e do Plano de Turma da qual faz parte, com a grande finalidade de organizar respostas educativas adequadas a cada aluno conforme as suas necessidades. Assim, as adaptações curriculares individuais devem ser 
realizadas, antes de mais, perante aquilo que o aluno consegue realizar junto dos seus pares e só depois aquilo que deve ser realizado de forma diferente e individualizada (MADUREIRA; LEITE, 2003).

Neste sentido, e tendo em conta o papel que a escola e o professor assumem neste processo, os contextos de decisão curricular passam essencialmente por dois diferentes níveis: o nível intermédio (a escola) e o nível concreto (a sala de aula), níveis onde se constrói o projeto de escola e o projeto didático ou de turma. A escola tem, assim, mecanismos próprios que lhe permite delinear um currículo adequado à realidade dos seus alunos.

A este propósito Manjón et al. (1993) e Correia et al. (2008) distinguem diferentes fases na concretização ou contextualização das adaptações curriculares a efetuar, propondo a sua flexibilização de modo a responder da forma mais adequada possível aos interesses, necessidades, ritmos de aprendizagem e experiências dos alunos. A primeira fase é ao nível do projeto curricular de escola (PCE), onde, de acordo com as características de cada escola, se definem os grandes blocos de objetivos e conteúdos que procuram dar resposta a todos os alunos que a frequentam. Segundo Manjón et al. (1993), as medidas aqui tomadas têm um papel importante na integração dos alunos com NEE, tanto ao nível da organização escolar, nomeadamente na tomada de decisões na identificação, avaliação e apoio aos alunos, de modo a facilitarem o acesso ao currículo a todos os alunos, especificamente aos alunos com NEE, que implica o trabalho em equipa na elaboração do modelo que a escola se propõe seguir, no seu desenvolvimento e nas alterações que virá a sofrer; como também ao nível dos serviços de orientação, que definem as condições para a aplicação das adequações ao currículo; passando ainda pelo nível dos serviços de tutoria, que inclui, por exemplo, a coordenação do papel dos professores envolvidos e o papel da família nos apoios a prestar.

O Projeto Curricular de Escola/Agrupamento (PCE) surge, assim, como parte integrante do Projeto Educativo de Escola/Agrupamento, corporizando a articulação entre este último e o currículo Nacional. Se assumirmos que ensinar é fazer aprender (Roldão, 1999), então o PCE pode ser definido como a orientação estratégica de uma organização escolar para fazer com que todos os seus estudantes aprendam os conhecimentos, procedimentos e atitudes prescritos no currículo nacional comum como socialmente necessários numa determinada época.

Vemos, por isso, que a existência de um PCE só faz sentido se este constituir verdadeiramente um documento que corporize opções de estratégicas de uma instituição escolar com vista à aprendizagem de todos os seus alunos. Estas opções terão que ter por base um conjunto de princípios, valores e orientações coletivamente discutidos e assumidos. Sem 
uma ideia clara e consciente dos problemas que cada organização escolar enfrenta, sem a promoção coletiva de princípios, valores e regras e sem a definição estratégica de uma linha orientadora para a superação das situações identificadas, o PCE será apenas uma compilação das metas de aprendizagem do currículo oficial comum, sem qualquer valor prático para os docentes, para os órgãos de gestão, para os alunos e para as suas famílias (Leite, 2011).

Mas para além do PCE, há decisões que passam pela organização da turma, onde Manjón et al. (1993), através da perspetiva de Rodriguez (1988), referem que este nível se organiza em três tipos de estratégias: a criação de ateliês, de projetos de investigação e programas específicos, para que o aluno com NEE participe no seio da sua turma. Leite (2011) refere que, ao nível da organização da turma, o Plano de Turma é também um processo e um produto coletivamente construído, passível de ser analisado, questionado, discutido e repensado em coletivo pelos docentes. Perante a complexidade das problemáticas que atualmente existem na população escolar e a diversidade de papéis que são conferidos ao professor, a colaboração entre profissionais, dentro da escola, deve ser uma prática orientadora da vida profissional do docente, já que é uma condição de eficácia da própria escola. Assim, o Plano de Turma define as prioridades da abordagem dos conteúdos de ensino, os processos interdisciplinares a garantir, a organização das sequências de atividades e os materiais de apoio a produzir e operacionaliza os processos de trabalho e de avaliação a desenvolver.

Do nível de concretização da turma, passa-se ao aluno individualmente e à necessidade dos ajustamentos e adequações curriculares que cada um precisa, no contexto da turma, e das atividades realizadas no quotidiano da escola. Desta análise pode fazer-se a leitura de que as decisões curriculares a nível da escola, da turma e do aluno configuram processos de adequação curricular progressivamente mais focados para as situações concretas.

$\mathrm{Na}$ verdade, os novos modelos pedagógicos, pretendem também ter uma vertente funcional, na medida em que desejam que os alunos desenvolvam, por um lado, as capacidades ao nível da autonomia pessoal e social e, por outro lado, promovam a sua inserção em serviços da comunidade, bem como proporcionem, sempre que possível, as mesmas oportunidades facultadas aos jovens da sua faixa etária. As aprendizagens partem, assim, das características e dos interesses dos jovens e são realizadas nos contextos da vida real onde pertencem, com o objetivo que consigam aí funcionar da forma mais autónoma possível (CORREIA et al., 2008).

Para tal, importa que a escola e a sociedade, tal como já se referiu, alarguem horizontes e se adaptem à verdadeira inclusão social. É preciso uma sociedade aberta à 
heterogeneidade de grupos que promova a participação e valorize a diversidade e experiências humanas. Para Nogueira e Andrade (2007), um processo de verdadeira inclusão social implica reformas estruturais no sistema educativo, renovando o modelo educacional, que proporcione a acessibilidade a todos, com o derrube de barreiras arquitetónicas, de atitudes negativistas e dos programas sem ambição. Neste contexto, a formação profissional assume uma importante relevância, pois é uma oportunidade para os jovens diferentes se capacitarem para o mercado de trabalho, o que só é possível com a alteração de paradigma, privilegiando as potencialidades.

A escola tem, desta forma, de estar atenta a todas estas dimensões e cabe-lhe a função de promover um plano de transição para a vida pós-escolar, desenvolvendo, assim, um currículo funcional adequado que, segundo Low Brown (1989, apud Bénard da Costa, 1996), deve respeitar algumas caraterísticas, entre outras, destacamos o facto do currículo funcional dever ser individualizado, deve incluir atividades funcionais, desenvolver-se, sempre que possível, em contextos não escolares e ao longo da vida, ir ao encontro das expectativas dos pais e dos alunos e deve conter itens que sejam suscetíveis de ser aprendidos pelo aluno num tempo razoável.

Importa, sobretudo, que os currículos funcionais tenham em conta que a transição para a vida ativa implique a preparação do jovem para um conjunto diversificado de realidades e, nesse sentido, para além da sua fundamental participação em classes regulares, acompanhando, tanto quanto possível o currículo comum, proponham que sejam estruturados conteúdos educativos que lhes permitam funcionar nos ambientes em que a generalidade das pessoas funciona (casa, comunidade, escola, trabalho e atividades de lazer). Para que isso aconteça, os educadores devem preparar essa intervenção, devem conhecer os ambientes em que o aluno funciona, de modo a que possam, posteriormente, pensar nas atividades que estes devem realizar nesses ambientes e prepará-los para o futuro e, desta forma, delinear as competências necessárias para empreender a aprendizagem em cada atividade (BÉNARD DA COSTA, 1996).

Segundo Brown (1989 apud FERREIRA, 2008), as principais características dos currículos funcionais são o facto de se tratar de currículos individualizados, ou seja, são adaptados a cada aluno, tendo em conta um determinado contexto familiar e social; são relacionados com a idade cronológica de modo a evitar a infantilização das crianças e assim promover e dignificar a sua auto-estima; estes currículos incluem tanto atividades úteis para a integração do aluno no seio da sociedade, como também atividades escolares, lúdicas, desportivas e socioculturais, fomentando, desta forma, a vivência de uma vida equilibrada. 
Neste sentido, vemos que o currículo funcional deve integrar um conjunto de competências de vida essenciais, tais como, as aptidões sociais (comunicação interpessoal, aparência aceitável e sensibilidade para com o outro), a gestão do dinheiro, do tempo e saber procurar emprego.

\section{A inserção no mercado de trabalho}

A importância cada vez maior que se atribui ao processo de escolarização, assim como o efeito da recessão económica que atualmente se vive, são fatores que têm vindo a atrasar, tal como já se mencionou, a idade de entrada no mercado laboral. Nesse sentido, a escola tem funcionado como "tampão" (AFONSO, 2005) relativamente à pressão social do desemprego. Todavia, esta conjuntura traduz-se em novos problemas, pois, permanecem mais tempo no ensino discentes a quem a escola "nada diz", alunos que não encontram na escola qualquer elemento motivador. Tal facto, derivado de uma política de uma escola de acesso livre para todos, leva a que alguns encarregados de educação procurem novos espaços elitistas para os seus filhos estudarem. Assistimos, desta forma, a um contrassenso, já que, ao mesmo tempo que a escola pública se vai tornando "inclusiva", esta vai perdendo um dos grupos sociais mais significativos, as elites, já que, habitualmente, são as famílias que económica e culturalmente têm mais posses as que com maior facilidade os seus filhos frequentam espaços de cultura. Ora se os alunos ditos "normais" se deparam com uma escola que se apresenta como "inclusiva", mas não lhes apresenta uma saída adequada, o problema adquire outras proporções no que diz respeito a alunos que requerem um acompanhamento mais específico e aprofundado.

Podemos encontrar uma série de obstáculos no acesso ao emprego por parte deste género de alunos, obstáculos esses que impossibilitam uma autêntica inserção no mercado laboral e que devem ser objeto de reflexão devido à importância que estes assumem nas vidas destes jovens. Segundo Azevedo (apud AFONSO, 2005), estes obstáculos poderiam resumirse da seguinte forma: falta de flexibilidade no ajustamento dos postos de trabalho e nos horários de trabalho; falta de informação e de visão dos empresários acerca da importância e das possibilidades de emprego de pessoas diferentes; relutância em investir nas adaptações necessárias à promoção do emprego de pessoas diferentes; falta de apoio financeiro aos empregadores para adaptar as instalações e criar os lugares de trabalho adequados; desconhecimento acerca dos sistemas de incentivos à contratação de pessoas diferentes e à adaptação de postos de trabalho; o desconhecimento acerca dos benefícios fiscais articulados ao emprego de pessoas diferentes. 


\section{Conclusão}

Procurou-se, ao longo destas páginas, compreender a forma como podem as escolas e os professores responder às exigências curriculares que advêm do processo, tanto necessário como indispensável, da inclusão, na contemporaneidade.

Concluiu-se que os processos inclusivos de diferenciação curricular implicam decisões fundamentadas e críticas sobre as adequações curriculares a realizar para o acesso ao currículo comum e sobre as formas específicas de desenvolvimento curricular. Não é um processo fechado, mas dinâmico, que implica tanto a capacidade da escola e dos professores como do próprio contexto envolvente. Todos estes intervenientes devem ter a capacidade de se adaptar às próprias exigências que a heterogeneidade escolar, típica da sociedade moderna, apresenta.

Verificou-se também, a partir da revisão da literatura, que têm sido vários os organismos nacionais, europeus e mundiais que formalmente têm debatido esta problemática e têm proposto alternativas para a inclusão e preparação para a vida pós-escolar dos alunos. Contudo, também se percebeu, que são ainda muitas as limitações que os diferentes intervenientes encontram para a obtenção do sucesso, que na maioria dos casos passa pela falta de respostas efetivas de recursos humanos e físicos adaptados às especificidades dos próprios alunos.

\section{REFERÊNCIAS}

AFONSO, C. Inclusão e mercado de trabalho - papel da escola na transição para a vida adulta de alunos com NEE. Saber (e) educar, n 10, p. 53-66, 2005.

AINSCOW, M. Understanding the development of inclusive schools. London: Falmer Press, 1999.

AINSCOW, M. Processo de Inclusão é um processo de aprendizado. Portal do Governo do Estado de São Paulo. Entrevista concedida à Secretaria de estado de Educação Especial, 2008. Disponível em: http://www.crmariocovas.sp.gov.br/ees_a.php?t=002. Acesso em: 12 fev. 2020.

ARISTÓTELES. Physique. Paris: Les belles Lettres, 1969.

BALZAC, H. A solteirona. Porto Alegre: Globo, 1951.

BAUTISTA, R. Necessidades educativas especiais. Lisboa: Dinalivro, 1993.

BECK, U. La sociedad del riesgo. Hacia una nueva modernidad. Barcelona: Paidós, 2006. 
BÉNARD DA COSTA, A.M. Currículo funcional no contexto da educação inclusiva. 2006. Disponível em: http://redeinclusao.web.ua.pt/files/fl_46.pdf. Acesso em: 12 fev. 2020.

BRENNAN, W. EI Currículo para niños com necesidades educativas especiales. Madrid: Siglo XXI España Editores, S.A., 1990.

CORREIA, L. et al. Intervenção com alunos com necessidades educativas especiais. In: CORREIA, L. M., Inclusão e Necessidades Educativas Especiais. Um guia para educadores e professores, 2. ed. revista e ampliada. Colecção Necessidades Educativas Especiais. Porto editora, 2008., p. 95-144.

CORREIA, L. Inclusão e necessidades educativas especiais: um guia para educadores e professores, 2. ed. Porto editora, 2008.

DECLARAÇÃO DE SALAMANCA. Revista Inovação, v. 7, n. 1, Ministério da Educação. Instituto de inovação educacional, 1994.

DECRETO-LEI n. 3/2008, de 7 de Janeiro de 2008. Diário da República, $1^{\mathrm{a}}$ série, n. $^{\circ} 4$. Lisboa: Ministério da Educação.

DUQUE, E. Contributos para uma crítica da aceleração do tempo. In: ARAÚJO, E.; DUQUE, E. (Org.), Os tempos sociais e o mundo contemporâneo. Um debate para as Ciências Sociais e Humanas. Braga: Centro de Estudos de Comunicação e Sociedade/Centro de Investigação em Ciências Sociais, 2012, p. 117-127.

DUQUE, E. É possível sair do presente? Uma teoria prospetiva. In ARAÚJO, E.; DUQUE, E; FRANCH J. DURÁN, M. (eds). Tempos Sociais e o Mundo Contemporâneo. As crises, As Fases e as Ruturas. Braga: Centro de Estudos de Comunicação e Sociedade/Centro de Investigação em Ciências Sociais, 2014, p. 154-169.

DURKHEIM, E. Historia de la educación y de las doctrinas pedagógicas. Madrid: La Piqueta, 1992.

EWEN, S. Consciences sous influence. Publicité et genèse de la société de consommation. Paris: Aubier, 1983.

FERNÁNDEZ ENGUITA, M. La cara oculta de la escuela. Educación y trabajo en el capitalismo. Madrid: SXXI, 1990.

FOUCAULT, M. Vigilar y castigar. Barcelona: Círculo de Lectores, 1999.

HABERMAS, J. O discurso filosófico da modernidade. Lisboa Publicações D. Quixote, 1990.

INNERARITY, D. O Futuro e os seus Inimigos. A paisagem temporal da sociedade contemporânea. Uma teoria da aceleração. Lisboa: Teorema, 2011.

LEITE, T. Diferenciação Curricular e NEE. In SIM-SIM, I. (Coord. e Int.). Necessidades Educativas Especiais: Dificuldades da Criança ou da escola? Coleção Educação Hoje. Lisboa: Texto Editores, 2005, p. 9-25. 
LEITE, T. Currículo e necessidades educativas especiais. Coleção Indução e Desenvolvimento Profissional Docente. Aveiro: Universidade de Aveiro, 2011.

MADUREIRA, I.; LEITE, T. Diferenciação Pedagógica: Preocupações e Dificuldades dos Professores. In: ESTRELA, A.; FERREIRA, J. (Coords), Diversidade e diferenciação em pedagogia. Atas do IX Colóquio da AFIRSE/AIPELF. Lisboa: FPCE, 2003.

MANJÓN, D; GIL, J.; GARRIDO, A. Adaptações Curriculares. In: BAUTISTA, R. (Coord.), Necessidades educativas especiais. Tradução e adaptação da 2. ed. atualizada: Ana Escoval. Lisboa: Dinalivro, 1993, p. 53-82.

NIZA, S. Necessidades especiais de educação: da exclusão à inclusão na escola comum. Inovação n. 9, Lisboa: Instituto de Inovação Educacional, 1996.

NOGUEIRA, F.; ANDRADE, L. A inclusão social das pessoas com deficiência no mercado de trabalho por meio da educação. Família e Sociedade. Universidade Católica de Minas Gerais, Arcos-MG, p. 1-6, 2007. Disponível em: http://www.psicologia.pt/artigos/textos/A0383.pdf. Acesso em: 12 fev. 2020.

ORTEGA, F. Sociología de la educación. Barcelona: Barcanova, 1993.

PACHECO, A. Currículo: teoria e práxis. Porto: Porto Editora, 2001.

PINAR, W. O que é a teoria do currículo? Porto: Porto Editora, 2007.

POLLARD, S. La génesis de la dirección de empresa moderna. Estudio sobre la Revolución Industrial en Gran Bretaña. Madrid: Ministerio de Trabajo y SS, 1987.

RODRIGUES, D. Perspectivas sobre a inclusão. Da educação à sociedade. Porto: Porto Editora, 2003.

RODRIGUES, D. Dez ideias (mal) feitas sobre a Educação Inclusiva. In: RODRIGUES, D. (ed.), Educação Inclusiva. Estamos a fazer Progressos? Cruz Quebrada: FMH Edições, 2006, p. 74-88.

ROLDÃO, M. Diferenciação curricular revisitada. Conceito, discurso e praxis. Porto: Porto Editora, 2003.

ROLDÃO, M. C. Os Professores e a gestão do currículo - perspectivas e práticas em análise. Porto: Porto editora, 1999.

SANTOS, B. As Tensões da modernidade. Trabalho apresentado no Fórum Social Mundial. Porto Alegre: Biblioteca das Alternativas, 2001.

SILVA, A. FRIAS. Adequações Curriculares e estratégias de ensino em turmas inclusivas: um estudo exploratório no $1^{\circ}$ ciclo. Dissertação apresentada à Escola Superior de Educação de Lisboa para obtenção do grau de mestre em ciências da educação especialização em educação especial, 2011. 
SILVA, T. Teorias do currículo. Porto: Porto editora, 2000.

SILVA, T.; MOREIRA, A. (Org.). Territórios contestados. O currículo e os novos mapas políticos e culturais. Petrópolis: Editora Vozes, 2001.

TORRES GONZÁLEZ, J. Educação e diversidade. Bases didácticas e organizativas. Porto Alegre: Artmed editora, 2002.

VARELA, J.; ÁLVAREZ-URÍA, F. Arqueología de la escuela. Madrid: La Piqueta, 1991.

WARNOCK, M. et al. Special Educational Needs. Report of Committee of Enquiry into the Education of Handicapped Children and Young People. London: HMSO, 1978.

WILLIS, P. Aprendiendo a trabajar. Madrid: Akal, 1988.

ZABALZA, M. Diversidade e Currículo Escolar: que Condições Institucionais para dar resposta à Diversidade da Escola. Lisboa: Ministério da Educação/Direcção Geral do Ensino Básico, 1999.

\section{Como referenciar este artigo}

DUQUE, Eduardo.; JF DURÁN VÁZQUEZ. O novo paradigma da educação na promoção de uma sociedade mais inclusiva. Revista Ibero-Americana de Estudos em Educação, Araraquara, v. 15, n. 1, p. 27-49, jan./mar. 2020. e-ISSN: 1982-5587. DOI: https://doi.org/10.21723/riaee.v15i1.12632

Submetido em: 05/06/2019

Aprovado em: 10/11/2019

Publicado em: 02/01/2020 